Reeve, D. (2012) 'Psycho-emotional disablism in the lives of people experiencing mental distress', in J. Anderson, B. Sapey and H. Spandler (eds) Distress or Disability? Proceedings of a symposium held at Lancaster Disability 15-16 November 2011, Lancaster: Centre for Disability Research, Lancaster University, pp. 24-29.

\title{
PSYCHO-EMOTIONAL DISABLISM IN THE LIVES OF PEOPLE EXPERIENCING MENTAL DISTRESS
}

\section{Introduction}

This discussion paper will introduce the concept of psycho-emotional disablism and then work through some of the questions that arose from my reading of '... distress or disability?'

(Plumb, 1994). I will show how psycho-emotional disablism has more potential relevance than structural disablism for those experiencing mental distress, because of the emphasis it places on barriers to being rather than restrictions of activity. Psycho-emotional disablism also fits comfortably alongside the existing social model of madness and distress which helps challenge internalised oppression. Finally I consider whether it is possible to completely eliminate the subject of 'impairment' from discussions of the experience of mental distress and end by suggesting some fruitful areas for further thought and discussion.

\section{Psycho-emotional disablism}

The term psycho-emotional disablism was originated by Carol Thomas (1999; 2007) as part of her project to unpack the different meanings that disability had come to have in academic and mainstream parlance. Drawing on the UPIAS (1976) statement which informed the social model of disability, instead Thomas proposes an extended social relational definition of disablism:

'Disablism is a form of social oppression involving the social imposition of restrictions of activity on people with impairments and the socially engendered undermining of their psycho-emotional well-being.' (Thomas, 2007: 73, my emphasis)

Consequently disablism can be broken down into two strands: structural disablism and psycho-emotional disablism. Structural disablism directly impacts on what people can do and refers to the disabling barriers which operate at the public level. For example exclusion from the built environment, discrimination in the work place or information in inaccessible formats, in other words, the disabling barriers typically associated with the social model of disability. On the other hand, psycho-emotional disablism operates at the private level, restricting who people can be. For example, having to deal with hurtful comments, stigmatising actions of others and internalised oppression which can undermine someone's psycho-emotional wellbeing and sense of self.

Whilst the social model does not deny the reality of psycho-emotional disablism, structural disablism has dominated academia, policy and grassroots activism with the consequence that psycho-emotional disablism and its long term consequences are overlooked. Part of this may be linked to the reluctance to engage with psychology because of the prevalence of individual tragedy models of disability and the association of disability with loss; however this has meant that the impact of psycho-emotional disablism on the lives of disabled people has been overlooked. Having to deal with the stares and comments of strangers can exclude someone from the built environment as effectively as a flight of stairs, showing how barriers to being can also result in barriers to doing. In addition, psycho-emotional disablism can be likened to emotional abuse because of its long-term and cumulative effects (Reeve, 2006) and consequently the ways in which someone deals with current psycho-emotional disablism could be expected to be impacted to some degree by prior experiences of abuse.

To date my work has looked at psycho-emotional disablism experienced by people with physical impairments (Reeve, 2008) and those with chronic illness which is often experienced as an invisible/fluctuating impairment (Reeve, forthcoming). Within disability studies, it has been identified that the survivor movement lacks representation within academic writing and that the disabled peoples 
movement still has a medicalised view of mental distress (Beresford, 2000). This short paper will present some initial thoughts on whether this different definition of disablism provided by Thomas has anything new/helpful to offer people experiencing mental distress - or does it remain part of the problem in the ways that the social model has been identified (Plumb, 1994).

\section{Psycho-emotional disablism and mental distress}

In terms of policy and legislation, people who are given the label of psychosis by the mental health system are identified as disabled people - whether or not they self-identify as such (Beresford, 2000). This brings a measure of protection against discrimination in the workplace although prejudice against this group of people remains firmly wedded to the medical model of madness as dangerous (Beresford, Nettle and Perring, 2010). In line with the findings that people are more prejudiced towards people with mental health conditions than those with physical or sensory impairments (Staniland, 2011), people with mental health conditions experience disproportionate rates of disablist hate crime compared to most other impairment groups (Sin, et al., 2009).

Disablist hate crime is an extreme form of psycho-emotional disablism carried out by a perpetrator whose actions are based at least in part, on their assumptions about the invalidity and less-than-human view of someone they perceive as disabled. It is not difficult to see the negative impact this form of psycho-emotional disablism has on emotional well-being if leaving the house makes one vulnerable to neighbours calling you names based on prejudices about mental health - 'psycho', 'nutter', 'freak', 'schizo' (Mind, 2007: 6). This experience of psycho-emotional disablism on a daily basis could be expected to exacerbate the experience of mental distress - an example of how disablism and 'impairment' can interact with each other.

Whilst I can see how the conventional social model of disability with its focus on removing structural barriers appears to have little to offer people experiencing mental distress, the notion of psycho-emotional disablism is far more pertinent to the daily harassments and prejudice that people with (perceived) mental distress experience regularly. By labelling this as a form of disablism, rather than 'just prejudice' (in the same way that yelling abuse based on skin colour would be called racism and not prejudice) then it is clear that the solution to these disabling psycho-emotional barriers lies in changing society and not the individual.

The social relational definition of disablism I have used to inform my analysis so far, is useful in one respect because it highlights disabling barriers which operate at both the public and private level - for people experiencing mental distress, it is forms of psycho-emotional disablism which are likely to be the most problematic and disabling. For example psychiatric diagnoses of mental distress that are presented solely in terms of incurable/hopeless illness which necessitates drug treatment could be seen as forms of institutional psycho-emotional disablism; this is analogous to the surgical interventions carried out on people with physical impairments to 'normalise' them so that they can be accepted back into society (Hughes, 2005). The ways in which people experiencing mental distress are seen as discreditable solely on the basis of a psychiatric label could also be viewed as institutional psychoemotional disablism.

However this definition of disablism which I am using here is still reliant on the presence of impairment - perceived/actual/past - which poses a problem for some such as Plumb (1994). The idea of impairment is obviously inappropriate for those people who see themselves as being different as opposed to a having a lack or illness. I think it is still true to say that strangers who shout abuse in the street (which I would usually term disablism) are acting on perceived/visible difference which is interpreted as impairment/illness. Although the terminology of 'impairment' and 'disablism' may not be right for people experiencing mental distress, nonetheless the same effects are at work and so a similar analysis may be useful. 


\section{The role of psycho-emotional disablism within a social model of madness and distress}

One of the most significant points that Plumb (1994: 4-5) makes is that mental distress is analogous to disablism rather than impairment, because the roots of that distress are to be found within relationships with society rather than a chemical imbalance or other label attached to the individual. The research carried out by Beresford et al (2010) showed that a social model of madness and distress cannot be simply derived from a social model of disability. This is because many people experiencing mental distress do not consider themselves to have an impairment; or if they do, then it is seen as socially constructed, fluctuating - not as 'objective' and 'measureable' as the sensory and physical impairments associated with a social model of disability approach to discrimination and oppression.

However a social model of some sort is needed to explain the experiences of discrimination and oppression which are left untouched by medical model views of the lives of people living with mental distress. It is also necessary to take account of individual needs and social circumstances as financial and social resources (such as supportive family, employment, housing) as these will have a significant impact on how mental distress is experienced.

Leaving aside the definitional problem I discussed earlier associated with the use of the term 'impairment', I suggest that the concept of psycho-emotional disablism is still useful here helping identify the roots of prejudicial attitudes and acts of invalidation experienced by people experiencing mental distress. Beresford et al (2010) conclude that a social model of madness and distress would be helpful in challenging internalised oppression - a form of psycho-emotional disablism which can happen when someone internalises the devalued and stigmatising messages about madness and mental distress.

'We are generally seen (even by ourselves?) as being at fault - 'not coping', 'not fitting in' of 'holding strange views' or 'behaving oddly'.' (participant in Beresford, Nettle and Perring, 2010: 18)

Internalised oppression is insidious and difficult to counter because it largely acts at an unconscious level. As well as having a potentially damaging impact on someone's selfesteem and sense of self, it is likely to exacerbate the level of mental distress experienced by increasing fear and anxiety levels - another example of disablism and impairment interacting together. Beresford et al (2010: 32) call for more attention to be paid to helping people challenge their own internalised oppression through support from survivor-led organisations and movement. This peer support can model alternative (more positive/healthy) ways of being to those reflected by medical diagnoses and headlines in the Daily Mail.

\section{New ways of being}

If mental distress has its roots in relationships that the individual has with society and others (past/present), then there is also a need to recognise diversity of 'being' in the true sense of the word. Unfortunately our society is not very accepting of difference, as one participant commented:

'We all identify with each other, but we don't live in a society, despite the facts that we speak about individuality, we really don't like difference, do we? Anybody who's slightly different, reacts differently, get 'em out as quickly as possible, or try and change them.' (participant in Beresford, Nettle and Perring, 2010: 26)

This is one of the points of departure from the social model of disability: whilst disabled people are fighting for inclusion into mainstream society, for others, it is the experience of being a round peg in a square hole which causes the mental distress in the first place (Plumb, 1994). Rather than being shaved down to fit the allotted hole, the fight is for a 'changed' society which recognises diversity 
and allows for new/creative ways of being. In many respects disabled people are already doing this e.g. parenting a child with the assistance of a team of personal assistants.

Psycho-emotional disablism stifles these creative ways of being that provide validation rather than rejection of the person experiencing mental distress. So for example, one of the important aspects of the Hearing Voices Network is listening to what the voices are saying and making sense of the role they play in someone's past/present life rather than simply silencing these inner voices with drugs (Hornstein, 2009). Ontological validation is important to people experiencing mental distress, particularly when they may have experienced years of having their fears and experiences labelled as unreal fantasies, delusions or symptoms by 'experts' (Kristiansen, 2004).

I wonder if it might not be helpful to consider some of the contemporary debates going on in the neurodiversity movement. In many ways the ontological questions being asked are similar - the valuing of neurodiverse ways of being alongside the conventional neurotypicallyinformed 'norms' of being (Boundy, 2008). In both cases disablism emerges when the behaviour and actions of those who are neurodiverse or are experiencing mental distress 'clash' with societal norms of behaviour (which of course vary with culture/time/place). This is substantially different to the case of other groups of disabled people where the disjuncture is more connected with societal norms of moving/perception/comprehension - and where the removal of disabling barriers is 'common sense' (Plumb, 1994: 14) such as installing a lift, making information accessible and the provision of tactile pavement edges at street crossings.

\section{Theoretical implications of mental distress for the disablism/impairment divide}

Whilst there has been a general consensus that a social model of madness and distress has value in recognising the social forms of oppression - discrimination and prejudicial attitudes that people experiencing mental distress face, the issue of 'impairment' never quite disappears. Some people who participated in the research reported earlier by Beresford et al were ambivalent about impairment - not liking the actual word but articulating a need for a term which was related:

'Well, l've always felt a bit uncomfortable about this, but it's there isn't it ... I mean there's an impairment that's imposed on people in some kind of way, I suppose it is the equivalent, it's not a very good word, but it is the equivalent.' (participant in Beresford, Nettle and Perring, 2010: 28)

This may have been due to a misunderstanding of what counts as disability or impairment hence my use of the term 'disablism' from the start of this paper to describe social forms of oppression. However Kristiansen (2004) in her work with women experiencing mental distress in Norway has a problem seeing impairment as purely social because it denies the reality of the distress which does not originate from society/relationships, but is sometimes intrinsic to the experience of mental distress. Recognising that 'impairment' is not as straightforward as paralysed limbs or poor vision, instead she suggests that it might be more helpful to see disability and impairment as blurred rather than the dichotomy suggested by traditional social model approaches. For example, one woman in her study described how:

'People I know avoid me on the streets, look the other way ... my doctor says I'm paranoid, oversensitive ... I don't feel I am, but I just don't know ... I don't think the medicine helps, but what else can I do?' (participant in Kristiansen, 2004: 379)

In reality, what is seen as being caused by 'impairment' and what is down to 'disability' is unclear as the two threads are tightly interwoven, and the debates have little real-world relevance to the mental distress these women are experiencing. 
The persistence of traces of 'impairment' in the accounts of those experiencing mental distress means that theoretical analyses need to include reference to impairment in some form or another. Elsewhere in this collection, Floris Tomasini discusses how mental distress can be seen as a direct challenge to the traditional dichotomies of mind/body, mental disorder/illness/distress, mental/physical dysfunction and he highlights the value of phenomenological approaches which recognise the interconnectedness of body-subject. Similarly Goodley presents examples of phenomenological approaches in disability studies which allow for theoretical analyses of the interconnections of body/society (see also Reeve, forthcoming).

Elsewhere I have suggested that one way of modelling the interconnections between psychoemotional disablism and impairment might be through the use of a Möbius strip (Reeve, 2011). If a strip of paper has disablism written on one side, and impairment on the other, then joining this into a simple loop maintains the clear separation of disablism and impairment as typified by a conventional social model understanding of disablism. However if a twist is inserted before joining the ends of the loop then a Möbius strip is created which has a continuous single edge, and single face. If one follows the face around the Möbius strip, then disablism merges into impairment which merges back again into disablism - there is no clear dividing line. Whilst the Möbius strip is not without criticism - see for example the caveats listed by Elizabeth Grosz (1994: 210) who used the Möbius strip for a feminist exploration of the gendered body - it would nonetheless be worth considering the following questions:

- To what extent can a Möbius strip offer flexibility in how 'impairment' and psychoemotional disablism are interconnected, as one can be at different points on the twisted loop?

- What can this offer the discussions of the part played by psycho-emotional disablism and 'impairment' in the experience of mental distress?

- Can it help resolve the thorny 'problem' of impairment?

However it should be borne in mind that although this kind of theorising supports the exploration of the continuum between disablism and impairment, it is still just another academic debate and potentially of limited use to those living in what Kristiansen (2004) calls 'mental health land'.

\section{Concluding thoughts}

As this is a piece of work in progress that illustrates the initial thinking I have done on the topic of psycho-emotional disablism in the lives of people experiencing mental distress, it seems most appropriate to finish with the questions that I am still grappling with since the symposium.

- Do we still need some kind of signifier for 'impairment'? Is it possible to theorise mental distress without it and still take account of what Kristiansen calls the 'intrinsic' aspects of mental distress for many people?

- Is it helpful to view the experience of mental distress as having different possible intersecting/fluctuating dimensions which include the following (in no particular order)

- Socially constructed aspects of impairment - for example the ways in which distress is seen as a difference to be chemically treated rather than understood as valid responses to trauma/life experiences.

- Psycho-emotional disablism - for example the invalidating responses of others based on cultural representations and myths about mental distress.

- Internalised oppression - psycho-emotional disablism arising from the internalisation of prejudices about mental distress. I have listed it here separately because in addition to the changes which need to be made at the society/media level to remove these prejudices, the survivor movement has much to offer in terms of modelling more positive ways of being in the world as a way of challenging this unconscious, but very damaging form of disablism. 
- Impairment effects (or should this be psycho-emotional aspects of impairment?) which directly addresses the point made by Kristiansen not to ignore the real emotional difficulties which can accompany mental distress. Here peer support groups would be helpful in offering coping strategies, but some people may want medical interventions to manage this.

\section{References}

Beresford, P. (2000) 'What have madness and psychiatric system survivors got to do with disability and disability studies?', Disability \& Society 15(1): 167-172.

Beresford, P., Nettle, M. and Perring, R. (2010) 'Towards a Social Model of Madness and Distress? Exploring What Service Users Say', York: Joseph Rowntree Foundation.

Boundy, K. (2008) '"Are you sure, sweetheart, that you want to be well?": An exploration of the neurodiversity movement', Radical Psychology 7(2): 2-2.

Grosz, E. (1994) Volatile Bodies: Towards a Corporeal Feminism, Bloomington, IN: Indiana University Press.

Hornstein, G. A. (2009) Agnes's Jacket, New York: Rodale.

Hughes, B. (2005) 'What can a Foucauldian analysis contribute to disability theory?', in S.

Tremain (ed.) Foucault and the Government of Disability, Ann Arbor, MI: University of

Michigan Press, pp. 78-92.

Kristiansen, K. (2004) 'Madness, badness, and saneness: Ontology control in 'mental health land", in K. Kristiansen and R. Traustadóttir (eds) Gender and Disability Research in the Nordic Countries, Lund, Sweden: Studentlitteratur, pp. 365-393.

Mind (2007) Another Assault: Mind's Campaign for Equal Access to Justice for People with Mental Health Problems, London: Mind.

Plumb, A. (1994)... Distress or Disability?, Manchester: GMCDP Publications.

Reeve, D. (2006) 'Towards a psychology of disability: The emotional effects of living in a disabling society', in D. Goodley and R. Lawthom (eds) Disability and Psychology: Critical Introductions and Reflections, London: Palgrave, pp. 94-107.

Reeve, D. (2008) Negotiating Disability in Everyday Life: The Experience of Psycho-

Emotional Disablism, PhD Thesis, Lancaster: Lancaster University.

Reeve, D. (2011) 'Psycho-emotional disablism and the 'dys-appearing' body: Implications for the disability/impairment divide', paper presented at Theorizing Normalcy and the Mundane (2nd international conference), Manchester Metropolitan University, 14-15 July (keynote). Reeve, D. (forthcoming) 'Psycho-emotional disablism: The missing link?', in N. Watson, A. Roulstone and C. Thomas (eds) Routledge Companion to Disability Studies, London: Routledge.

Sin, C. H., et al. (2009) Disabled People's Experiences of Targeted Violence and Hostility (Research Report 21), Manchester: Office for Public Management.

Staniland, L. (2011) Public Perceptions of Disabled People: Evidence from the British Social Attitudes Survey 2009, London: ODI.

Thomas, C. (1999) Female Forms: Experiencing and Understanding Disability, Buckingham: Open University Press.

Thomas, C. (2007) Sociologies of Disability and Illness: Contested Ideas in Disability Studies and Medical Sociology, Basingstoke: Palgrave Macmillan.

UPIAS (1976) Fundamental Principles of Disability, London: The Union of the Physically Impaired Against Segregation and The Disability Alliance. 